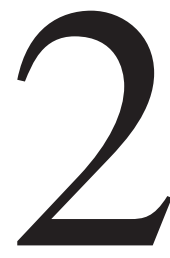

Phenotypic plasticity revealed by molecular studies on reef corals of Fungia (Cycloseris) spp. (Scleractinia: Fungiidae) near river outlets

Adriaan Gittenberger and Bert W. Hoeksema 


\title{
Phenotypic plasticity revealed by molecular studies on reef corals of Fungia (Cycloseris) spp. (Scleractinia: Fungiidae) near river outlets
}

\author{
Adriaan Gittenberger and Bert W. Hoeksema \\ National Museum of Natural History, P.O. Box 9517, NL 2300 RA Leiden. \\ gittenbergera@naturalis.nnm.nl
}

Key words: eco-phenotype; plasticity; allozymes; river outlets; mushroom corals; Fungiidae; Cycloseris; Indonesia

\begin{abstract}
On a patch reef off Makassar, Sulawesi, Indonesia, corals identified as Fungia (Cycloseris) costulata, Fungia (Cycloseris) tenuis and Fungia (Cycloseris) cf costulata were collected down to a maximum depth of $10 \mathrm{~m}$. The corals lived sympatrically. Mushroom coral clones resulting from fragmentation can be recognized by their equal coloration and close proximity. Therefore, to ensure that no clones were collected, corals of dissimilar colors were selected at a mutual distance of $5 \mathrm{~m}$. The corals were kept alive in two 30 liter sea-water aquariums with an air-pump. They were photographed in detail. Using allozyme electrophoresis in a laboratory close to the field area, it was tested whether the separate coral morphs should be considered three species. Eventually it was concluded that there are only two species, i.e. F. (C.) costulata and F. (C.) tenuis, of which F. (C.) costulata has two distinct morphs, one of which may be an eco-phenotype occurring on reefs off river outlets or inside estuaries.
\end{abstract}

\section{Contents}

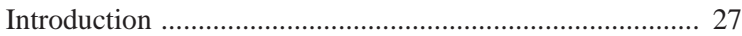

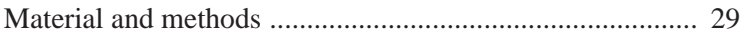

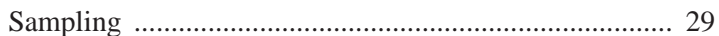

Allozyme electrophoresis ............................................. 29

Data analyses ............................................................. 30

Morphological investigations ....................................... 31

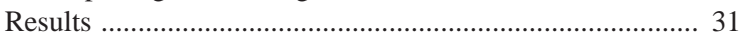

Morphology ...................................................................... 31

Allozyme electrophoresis ............................................ 31

Discussion ........................................................................ 31

Acknowledgements ................................................... 32

References ..................................................................... 32

\section{Introduction}

Intraspecific variation in scleractinian corals is a classic problem in their taxonomy, both in regard to recent and fossil species (Best et al., 1999; Knowlton and Budd, 2001). Habitat-induced variability has been observed in coral species distributed along depth ranges, in which the specimens from the deeper sites used to be flatter than those from shallower places. The former ones exposing more surface area in order to compensate for less light penetration at greater depths (Wijsman-Best, 1972, 1974; Hoeksema, 1993). Other environmental factors of importance in coral shape plasticity may be sedimentation, salinity and water temperature, turbulence and flow; in addition to coral morphology also the pigmentation in the soft tissue may be affected (Bruno and Edmunds, 1997; Todd et al., 2002a, 2002b, 2004b, 2004c). Coral damage and subsequent regeneration also have specific effects on shape, which may impede taxonomy and easy identification (Hoeksema, 1989, 1991b, 1993; Oren et al., 1997; Nagelkerken and Bak, 1998).

For no obvious reason, most of the research on intraspecific coral variation has been performed on massive faviids, both in the Atlantic (Dustan, 1975; Foster, 1977, 1979; Lasker, 1981; Graus and Macintyre, 1982; Dodge, 1992; Beltran-Torres and Carricart-Gavinet, 1993; Amaral, 1994; Manica and Carter, 2000) and the Indo-Pacific (Wijsman-Best, 1972, 1974; Miller, 1994; Oren et al., 1997; Todd et al., 2001, 2002a, 2002b, 2004a, 2004b, 2004c). Mushroom corals (Fungiidae), which are endemic to the Indo-Pacific, have mainly been studied in relation with light penetration, sedimentation, and traumatic damage (Hoeksema, 1989, 1991b, 1993; Hoeksema and Moka, 1989). A physiological difference with regard to vulnerability to elevated temperature has also been shown among individuals of the same mushroom coral species within close range of each other (Hoeksema, 1991a). 
During earlier taxonomic and morphological studies on mushroom corals three different morphs of Fungia (Cycloseris) spp. were distinguished (Hoeksema, 1989; Hoeksema and Moka, 1989). Two of these were considered separate species, viz.Fungia (Cycloseris) costulata Ortmann, 1889 (figs 1-2), and F. (C.) tenuis Dana, 1864 (figs 7-8); the third one was seen as a morph of the first (figs 3-6; Hoeksema and Moka, 1989: fig. 12). Fungia (C.) tenuis has much rougher costae and usually a slightly different coloration (dark brown stomatal ends) as compared to $F$. (C.) costulata. The two are usually observed on the same reefs. However, F. (C.) costulata may also be present on reefs that are more nearshore, in more sediment-rich water, and they may occur deeper when found on the same reef as F. (C.) tenuis. The alleged separate morph of $F$. (C.) costulata is thinner and shows an evenly brownolive green color (figs 3-6). It occurs on nearshore reefs, either on patch reefs near river outlets or inside deep bays and estuaries. The three morphs cannot always be distinguished easily. Therefore, in order to investigate the taxonomic implications of the morphological differences, several allozymes of the morphs were compared. Allozyme electrophoresis has successfully been used to solve similar taxonomical problems (Gittenberger et al., 2001; Sanjuan et al., 1997). The three morphs will be referred to as morphs A, B and C for respectively Fungia (Cycloseris) costulata, F. (C.) tenuis and F. (C.) cf costulata.

\section{Material and methods}

\section{Sampling}

Specimens of morphs A, B and C were found sympatrically at Bone Baku reef, off Makassar, Sulawesi, Indonesia. Twelve specimens of each morph were collected within an area of about $200 \mathrm{~m}^{2}$ at depths between 2 and 12 meters. They were coded A1-12, B1-12 and C1-12. To make sure that no clones were included, only individuals that differed in polyp coloration were selected. While diving, the specimens were individually put into separate plastic bags and transported to the laboratory in a bucket with seawater. They were kept alive in two 30 liter aquariums with two air-pumps each. To reduce the pollution in the aquariums, the water was taken a few kilometers off the coast and filtered through a coffee filter. Before the allozyme electrophoresis, all corals were digitally photographed on both sides with a Fujifilm MX2700 camera.

\section{Allozyme electrophoresis}

Each coral was taken out of the aquarium. After that half a $1.5 \mathrm{ml}$ test-tube of coral tissue mixed with small pieces of skeleton was rasped of the septae with a scalpel, and $0.050 \mathrm{ml}$ of homogenizing buffer (0.01M Tris, 0.001 M NaEDTA, 0.01 M Maleic acid and $0.001 \mathrm{M} \mathrm{MgCl2}$ ) was added. The mixture was ground with a micro-pestle and put on ice. The damaged specimens were digitally photographed on both sides and conserved in 96\% alcohol, as reference material. To create a centrifuge, the blades of a small table-ventilator were removed and the tubes were stuck to the spindle with heavy duty tape. Each sample was centrifuged for 30 seconds at maximum speed. The supernatants were extracted with a 0.100 $\mathrm{ml}$ pipette and added to a new tube, which was centrifuged for 30 seconds and put on ice.

Occasionally the supernatant was too slimy (highly viscose and sticky) to be extracted into a $0.100 \mathrm{ml}$ pipette point. In that case, the top of this pipette point was cut off with a scalpel to enable the extraction of the "slimy" supernatant into a new tube. An additional $0.050 \mathrm{ml}$ homogenization buffer was added and everything was mixed by sucking it up and down into the cut pipette point. After centrifuging this mixture at maximum speed for 30 seconds, the supernatant could be extracted with a $0.100 \mathrm{ml}$ pipette point. It was added to a new tube and put on ice.

The slots of a well-plate were filled with $0.010 \mathrm{ml}$ supernatant each. An applicator was used to load and apply the supernatant to a cellulose acetate gel (Hillis et al., 1987). Supernatants of all samples were run on a gel for 25 minutes and on an additional gel for 40 minutes. The electrophoresis was performed in a refrigerator at $4^{\circ} \mathrm{C}$.

To test which allozyme systems in combination with which running buffers work best for Fungiidae, i.e. show polymorphic loci with a good resolution and activity, a preliminary study was done in the Netherlands. In total 10 allozyme systems were tested on two specimens of Heliofungia actiniformis (Quoy and Gaimard, 1833) and two specimens of 

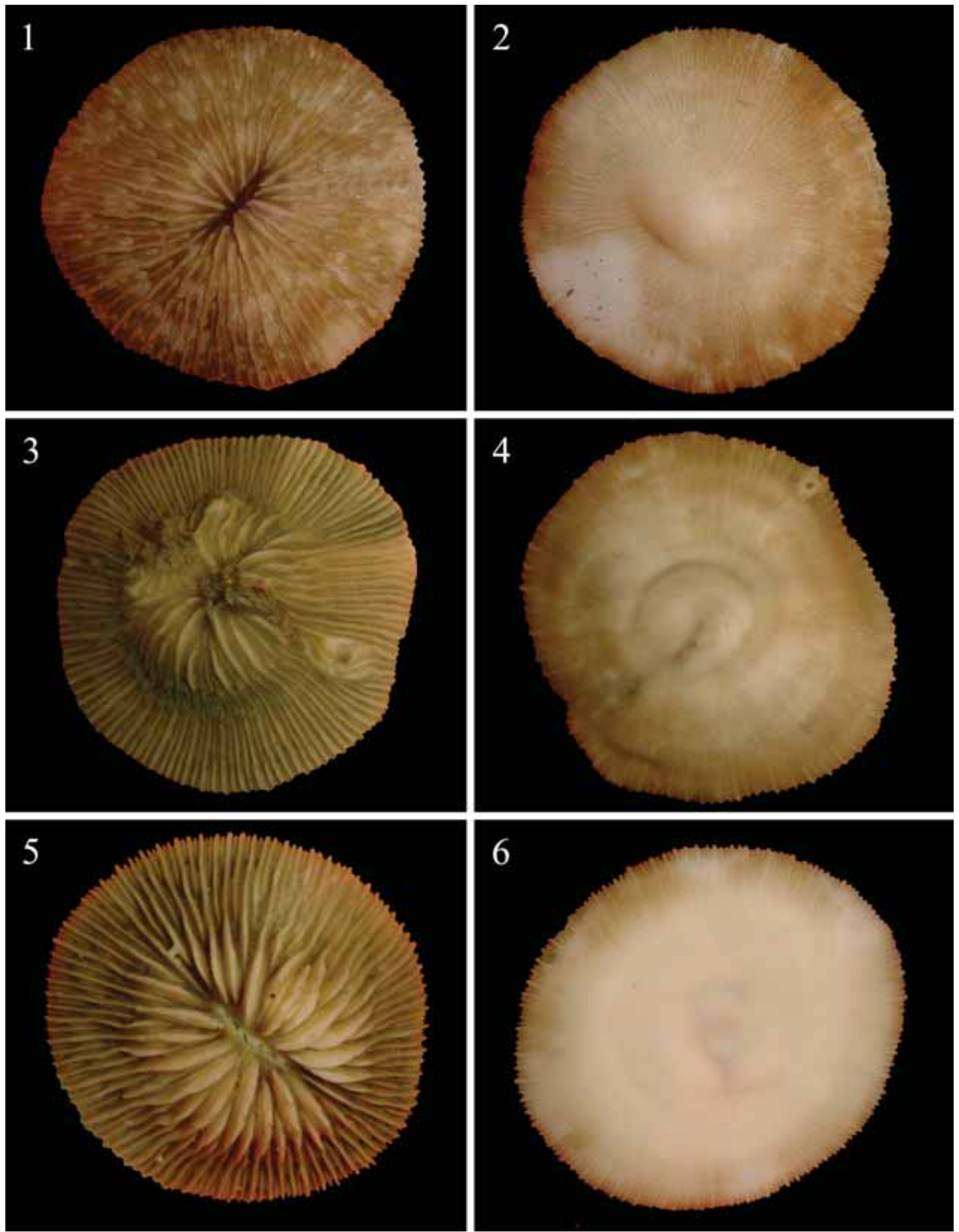

Figs 1-6. Upper and lower surfaces of mushroom corals. 1-2, Fungia (Cycloseris) costulata. 3-6, Fungia (Cycloseris) cf costulata. Scale = 1:1. 
Fungia (Verrillofungia) repanda Dana, 1846, viz. apartate aminotransferase (sAAT 2.6.1.1), alcohol dehydrogenase (ADH, 1.1.1.1), glucose dehydrogenase (GCDH, 1.1.1.118), glucose 6 phosphate dehydrogenase (G6PDH, 1.1.1.49), hexokinase (HK, 2.7.1.1), L-iditol dehydrogenase (IDDH, 1.1.1.14), isocitrate dehydrogenase (IDH, 1.1.1.42), malate dehydrogenase (MDH, 1.1.1.37), glucose-6-phosphate isomerase (GPI, 5.3.1.9), and phospho-glucomutase (PGM, 5.4.2.2). The nomenclature and IUBNC numbers are according to those of the standard of the International Union of Biochemistry (IUBNC, 1984). All allozyme systems were tested in combination with three buffers (Saccheri, 1995), i.e. TG (pH 8.5, 25mM Tris, 192 mM Glycine), TM (pH 7.8, 50 mM Tris, 20 $\mathrm{mM}$ Maleic acid) and $\mathrm{P}(\mathrm{pH} 7.0,11.6 \mathrm{mM}$ Na2HPO4.2H2O, 8.4 mM NaH2PO4.H2O). The loci of the allozyme systems G6PDH, HK, MDH and GPI were polymorphic, with a good activity and a reasonable resolution using TM, TM, TG and P buffer respectively. The chemicals to test these allozyme systems were either bought in Indonesia or imported ice-packs from the Netherlands. These allozyme system-buffer combinations also gave good results during an additional test in Indonesia for specimens of Herpolitha limax (Esper, 1797), Zoopilus echinatus Dana, 1846, Fungia (Danafungia) fralinae Nemenzo, 1955, F. (D.) scruposa Kluzinger, 1879, F. (Pleuractis) gravis Nemenzo, 1955, F. (Verrillofungia) repanda Dana, 1846 and F. (V.) scabra Döderlein, 1901. A spider extract was used as a reference and positive control in all analyses. It showed a good activity and resolution for the allozyme system-buffer combinations described above. Unexpectedly, none of the specimens of morphs A, B or C showed any clear bands. Therefore, the allozyme system-buffer combinations were tested again for these corals. A good activity and reasonable resolution was only seen for the PGI allozyme system in combination with TG buffer. It showed one polymorphic and one homomorphic locus and was studied for the three morphs. The spider extract showed 4 bands with a high activity and good resolution and was used as a reference.

Data analyses

The resulting bands for each specimen were scored independently on two gels which had run for 20 and 40 minutes respectively. The bands that were scored twice were used for further analysis. The package of Swofford and Selander (1981), BIOSYS-1, was used to analyse the data. The exact probability test was used to test for Hardy-Weinberg at the polymorphic locus.

\section{Morphological investigations}

All the corals used in the experiment were investigated and identified morphologically in the field and, independently, from the photographs.

\section{Results}

\section{Morphology}

Except for the morphological differences described in the introduction, two additional characters distinguishing between $\mathrm{A}$ and $\mathrm{B}$ on the one hand, and $\mathrm{C}$ on the other hand were noticed.

It took about 2 minutes per specimen of the morphs A and $C$ to scrape off sufficient tissue mixed with septal skeleton pieces to fill half a $1.5 \mathrm{ml}$ tube, while it only took about 15 seconds for each specimen of $\mathrm{B}$, indicating that the skeletal structure of $\mathrm{B}$ was weaker. Furthermore, all specimens of only the morphs A and $\mathrm{C}$ had slimy mucous for which the protocol had to be adjusted (see "Material and methods section").

\section{Allozyme electrophoresis}

The frequencies of the 6 alleles found for the polymorphic locus of PGI are shown in Table 1. The alleles A, D and F, accounting for $77 \%$ of all alleles scored for morph B, are not present in A and C. The alleles B and C, accounting for respectively $100 \%$ and $90 \%$ of the alleles in the samples in morphs $A$ and $\mathrm{C}$, account for only $9 \%$ of the alleles in morph $\mathrm{B}$.

None of the three samples A, B and C (respectively $\mathrm{p}=0.57,1.00$ and 0.48 ) was significantly $(\alpha=0.05)$ deviating from Hardy-Weinberg. However, when pooling the samples, the frequencies of the alleles were significantly $(p=0.02)$ deviating for the 
Table 1 Frequencies of the alleles for the PGI allozyme system.

\begin{tabular}{|l|l|l|l|}
\hline & \multicolumn{3}{|c|}{ Sample } \\
\hline Allele & $F_{\text {. }(\text { C. }) \text { costulata }}$ & $F_{\text {. }(\text { C. }) \text { cf costulata }}$ & F. $($ C. $)$ tenuis \\
\hline (N) & 10 & 9 & 11 \\
\hline A & 0.000 & 0.000 & 0.045 \\
\hline B & 0.300 & 0.500 & 0.045 \\
\hline C & 0.600 & 0.500 & 0.045 \\
\hline D & 0.000 & 0.000 & 0.591 \\
\hline E & 0.100 & 0.000 & 0.136 \\
\hline F & 0.000 & 0.000 & 0.136 \\
\hline
\end{tabular}

sample $A+B+C$, almost significantly (respectively $p$ $=0.06$ and $\mathrm{p}=0.12)$ for $\mathrm{A}+\mathrm{B}$ and $\mathrm{B}+\mathrm{C}$, and not $(\mathrm{p}=$ 0.35 ) for $\mathrm{A}+\mathrm{C}$. This indicates that the samples $\mathrm{A}, \mathrm{B}$, $\mathrm{C}$ and $\mathrm{A}+\mathrm{C}$ can each be considered representatives of single demes, while the samples in which morph $\mathrm{B}$ was pooled with the morphs A and C cannot.

Nei's genetic distances (D), ranging between 0.02 and 0.32 , and Rogers' genetic distances, ranging between 0.087 and 0.317 , are shown in table 2 . The dendrogram (fig. 9) resulting from an UPGMA on Rogers' genetic distances has a very high cophenetic correlation (0.99), indicating that it accurately reflects the pattern of genetic variation in the matrix of genetic distances (Sneath and Sokal, 1973). An UPGMA using Nei’s genetic distances gave similar results.

\section{Discussion}

The fact that the allozyme system buffer combinations that work best for Fungia (Danafungia) fralinae, F. (D.) scruposa, F. (Pleuractis) gravis, $F$. (Verrillofungia) repanda and F. (V.) scabra do not give any clear results for the Fungia (Cycloseris) specimens, could be an indication that the allozymes of the latter taxon differ considerably from those of the former taxa. Therefore it might be more appropriate

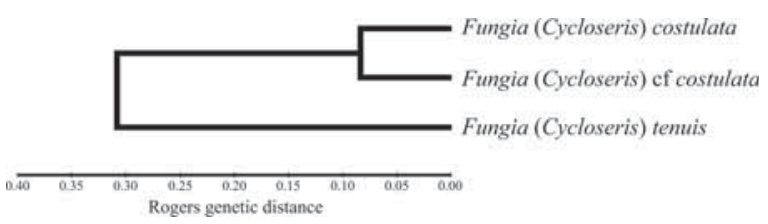

Fig. 9. UPGMA dendrogram based on Rogers' genetic distances for the three samples (cophenetic correlation $=0.99$ ).

to refer to Cycloseris as a genus. DNA-analyses of Fungiidae also support this view (Chapter 3).

A significant deviation of Hardy Weinberg was found when the alleles of all the specimens were pooled. This indicates that they should not be considered representatives of a single panmictic population. No proof was found for a reproduction barrier between $F$. (C.) costulata offshore morphs and $F$. (C.) costulata nearshore morphs. Pooling their alleles, no deviation of Hardy Weinberg was found. They should therefore be referred to as phenotypes within $F$. (C.) costulata.

Nei's and Rogers' genetic distances and the resulting dendrogram (fig. 9) clearly show that there is very little to no gene flow between $F$. (C.) tenuis and $F$. (C.) costulata at Bone Baku reef. In total $77 \%$ of all alleles scored for $F$. (C.) tenuis were not present in the specimens of both forms of $F$. (C.) costulata, and vice versa $95 \%$ of the alleles scored for F. (C.) costulata were only accounting for $9 \%$ in $F$. (C.) tenuis. These results combined with the morphological differences, i.e. the roughness of the costae, the mouth coloration, skeletal strength and sliminess of the mucus, support the view that Fungia (Cycloseris) costulata Ortmann, 1889, and F. (C.) tenuis Dana, 1864, are two valid species; and that $F$. (C.) costulata has a nearshore ecomorph that may be related to low-salinity sea water.

\section{Acknowledgements}

We would like to thank drs P. v. Bragt from the Hoge Laboratorium School, Breda, the Netherlands, for pro-

Table 2 Rogers' (below diagonal) and Nei’s (above diagonal) genetic distances between the samples.

\begin{tabular}{|l|l|l|l|}
\hline Sample & F. $($ C. $)$ costulata & F. $($ C. $)$ cf costulata & F. $($ C. $)$ tenuis \\
\hline F. $($ C. $)$ costulata & 0 & 0.02 & 0.30 \\
\hline F. $($ C. $)$ cf costulata & 0.09 & 0 & 0.32 \\
\hline F. $($ C. $)$ tenuis & 0.31 & 0.32 & 0 \\
\hline
\end{tabular}



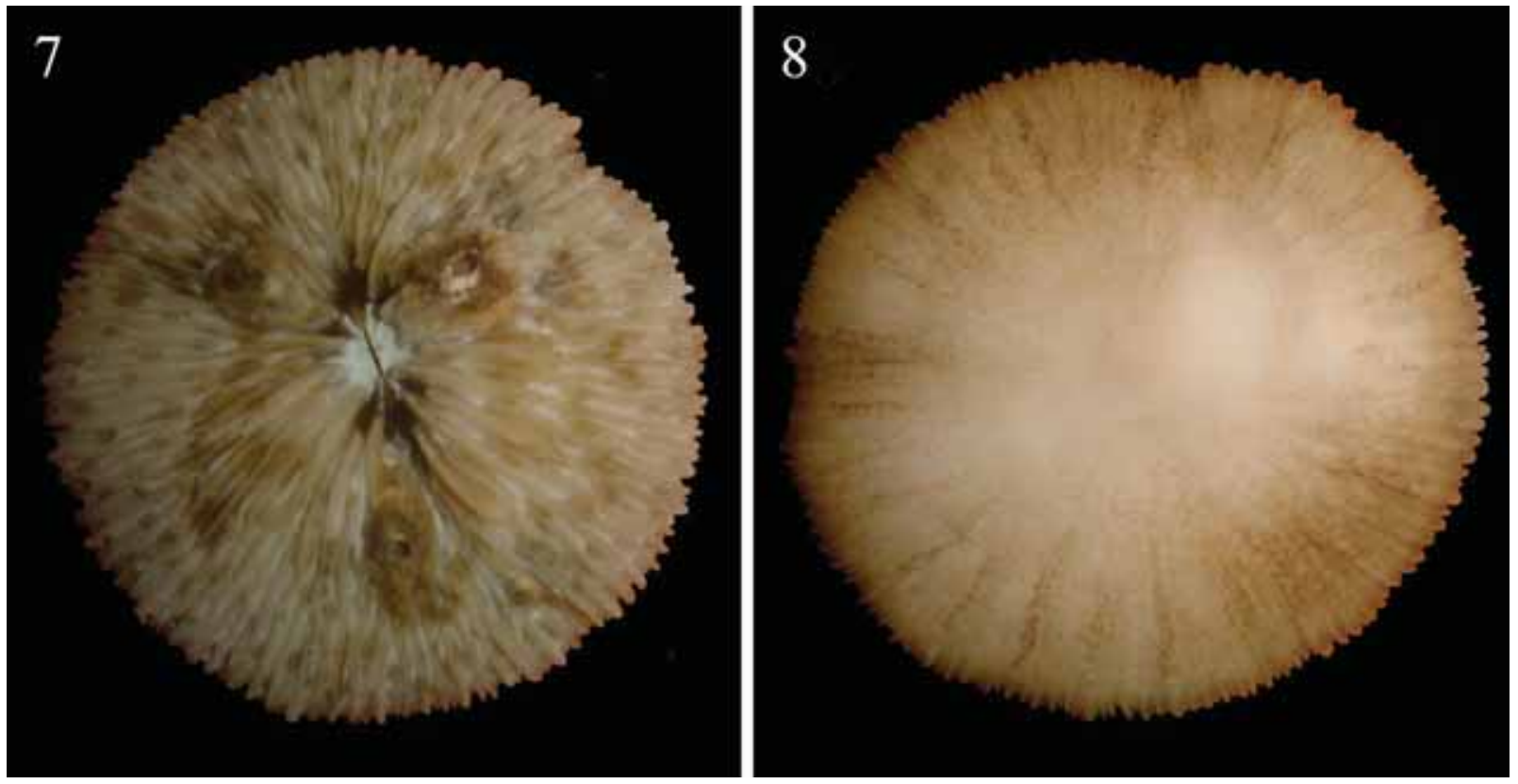

Figs 7-8. Upper and lower surface of Fungia (Cycloseris) tenuis. Scale = 1:1.

viding the space and equipment to do the preliminary allozyme electrophoresis study in the Netherlands. Dr. A. Noor is thanked for his help concerning the permits and facilities enabling research off Makassar, Indonesia. This study was supported by WOTRO (grant nr. W 82-249).

\section{References}

Amaral, F.D., 1994. Morphological variation in the reef building coral Montastrea cavernosa in Brasil. Coral Reefs 13: 113-117.

Best, M.B., G.J. Boekschoten \& A. Oosterbaan, 1999. Species concept and ecomorph variation in living and fossil Scleractinia. Paleonotographica Americana 54: 70-79.

Beltran-Torres, A.U. \& J.P. Carricart-Gavinet, 1993. Skeletal morphological variation in Montastrea cavernosa (Cnidaria: Scleractinia) at Isla Verde Coral Reef, Veracruz, Mexico. Revista de Biologia Tropical 41: 559-562.

Bruno, J.F. \& P.J. Edmunds, 1997. Clonal variation for phenotypic plasticity in the coral Madracis mirabilis. Ecology 78: 2177-2190.

Dodge, R.E., 1982. Effects of drilling mud on the reef-building coral Montastrea annularis. Marine Biology 71: 141-147.

Dustan. P., 1975. Growth and form in the reef-building coral Montastrea annularis. Marine Biology 33: 101-107.

Foster, A.B., 1977. Patterns of small-scale variation of skeletal morphology within the scleractinian corals Montastrea an- nularis and Siderastrea siderea. Proceedings 3rd International Coral Reef Symposium, Miami 2: 409-415.

Foster, A.B., 1979. Phenotypic plasticity in the reef corals Montastrea annularis and Siderastrea siderea. Proceedings 3rd International Coral Reef Symposium, Miami 2: 409-415. Journal of Experimental Marine Biology and Ecology 39: 25-54.

Gittenberger, A., K. Vrieling \& E. Gittenberger, 2001. Restricted gene flow between two alleged subspecies of Albinaria cretensis (Gastropoda, Pulmonata, Clausiliidae). Netherlands Journal of Zoology 51 (1): 71-84.

Graus, R.R. \& I.G. Macintyre, 1982. Variation in the growth forms of the reef coral Montastrea annularis (Ellis and Solander): a quantitative examination of growth response to light distribution using computer simulation. Smithsonian Contribution to Marine Science 12: 441-464.

Hillis, D.M., D.S. Rosenfield \& M. Sanches, 1987. Allozymic variability and heterozygote deficiency within and among morfologically polymorphic populations of Liguus fasciatus (Mollusca:Pulmonata:Bulimulidae). American Malacological Bulletin 5: 153-157.

IUBNC, 1984. International Union of Biochemistry: Nomenclature Committee. 1984. Enzyme Nomenclature, 1984. Academic Press, Orlando, Florida.

Hoeksema, B.W., 1989. Taxonomy, phylogeny and biogeography of mushroom corals (Scleractinia: Fungiidae). Zoologische Verhandelingen, Leiden 254: 1-295.

Hoeksema, B.W., 1991a. Control of bleaching in mushroom coral populations (Scleractinia: Fungiidae) in the Java Sea: stress tolerance and interference by life history strategy. Marine Ecology Progress Series 74: 225-237. 
Hoeksema, B.W., 1991b. Evolution of body size in mushroom corals (Scleractinia: Fungiidae) and its ecomorphological consequences. Netherlands Journal of Zoology 41: 122-139.

Hoeksema, B.W., 1993. Phenotypic corallum variability in Recent mobile reef corals. Courier Forschungs Institut Senckenberg 164: 263-272.

Hoeksema, B.W. \& W. Moka, 1989. Species assemblages and ecomorph variation of mushroom corals (Scleractinia: Fungiidae) related to reef habitats in the Flores Sea. Netherlands Journal of Sea Research 23: 149-160.

Knowlton, N. \& A.F. Budd, 2001. Recognizing coral species past and present. In: J.B.C. Jackson, S. Ligard \& F.K. McKinney (eds.), Evolutionary patterns: Growth, form, and tempo in the fossil record. Univ. Chicago Press, Chicago: 97-119.

Lasker, H.R., 1981. Phenotypic variation in the coral Montastrea cavernosa and its effect on colony energetics. Biological Bulletin 160: 292-302.

Manica, A. \& R.W. Carter, 2000. Morphological and fluorescence analysis of the Montastrea annularis complex. Marine Biology 137: 899-906.

Miller, K.J., 1994. Morphological variation in the coral genus Platygyra: environmental influences and taxonomic implications. Marine Ecology Progress Series 110: 19-28.

Nagelkerken, I. \& R.P.M. Bak, 1998. Differential regeneration of artificial lesions among sympatric morphs of the Caribbean corals Porites astreoides and Stephanocoenia michelinii. Marine Ecology Progress Series 163: 279-283.

Oren, U., Y. Benayahu \& Y. Loya, 1997. Effect of lesion size and shape of regeneration of the Red Sea coral Favia favus. Marine Ecology Progress Series 146: 101-107.

Saccheri, I.J., 1995. An experimental study of the effects of population bottlenecks on genetic variation and fitness in the butterfly Bicyclus anynana (Satyridae) Thesis. University of London, London.

Sanjuan, A., M. Pérez-Losada \& E. Rolan, 1997. Allozyme evidence for cryptic speciation in sympatric populations of Nassarius spp. (Mollusca: Gastropoda). Journal of the Marine Biological Association of the United Kingdom 77: 773-784.

Sneath, P.H.A. \& R.R. Sokal, 1973. Numerical taxonomy. Freeman, San Francisco.

Swofford, D.L. \& R.B. Selander, 1981. BIOSYS-1: A FORTRAN program for the comprehensive analysis of electrophoretic data in population genetics and systematics. Journal of Heredity. 72: 281-283.

Todd, P.A., P.G. Sanderson \& L.M. Chou, 2001. Morphological variation in the polyps of the scleractinian coral Favia speciosa (Dana) around Singapore. Hydrobiologia 444: 227235.

Todd, P.A., R.C. Sidle, \& L.M. Chou, 2002a. Plastic corals from Singapore: 1. Coral Reefs 21: 391-392.

Todd, P.A., R.C. Sidle, \& L.M. Chou, 2002b. Plastic corals from Singapore: 2. Coral Reefs 21: 407-408.

Todd, P.A., R.J. Laddle, N.J.I. Lewin-Koh \& L.M. Chou, 2004a. Flesh or bone? Qunatifying small-scale coral morphology using with-tissue and without-tissue techniques. Marine Biology 145: 323-328.

Todd, P.A., R.J. Laddle, N.J.I. Lewin-Koh \& L.M. Chou, 2004b. Genotype x environmental interactions in transplanted clones of the massive corals Favia speciosa and Diploastrea heliopora. Marine Ecology Progress Series 271: 167-182.

Todd, P.A., R.C. Sidle, \& N.J.I. Lewin-Koh, 2004c. An aquarium experiment for identifying the physical factors inducing morphological change in two massive scleractinian corals. Journal of Experimental Marine Biology and Ecology 299: 97-113.

Wijsman-Best, M., 1972. Systematics and ecology of New Caledonian Faviinae (Coelenterata - Scleractinia). Bijdragen tot de Dierkunde 42: 3-90.

Wijsman-Best, M., 1974. Habitat-induced modification of reef corals (Faviidae) and its consequences for taxonomy. Proceedings 2nd International Coral Reef Symposium, Brisbane 2: 217-228. 
